\title{
Compatibility between entomopathogenic fungi and biorational insecticides in toxicity against Ronderosia bergi under laboratory conditions
}

\author{
Sebastian A. Pelizza • A. C. Scorsetti • \\ M. N. Fogel $\cdot$ S. G. Pacheco-Marino • \\ S. A. Stenglein - M. N. Cabello - C. E. Lange
}

Received: 2 July 2014/Accepted: 22 July 2014/Published online: 6 August 2014

(C) International Organization for Biological Control (IOBC) 2014

\begin{abstract}
Our aim was to evaluate the efficacy of combinations between two biorational insecticides (luphenuron, methoxyfenozide), a new synthetic chemical pesticide (rynaxypyr), and three entomopathogenic fungi strains (Beauveria bassiana LPSc 1067, LPSc1082), and Metarhizium anisopliae (LPSc 907) in the biocontrol of the pest grasshopper Ronderosia bergi (Stål) under laboratory conditions. The insecticides were tested at three concentrations: the average concentration recommended for application in the field (100\%) and $50 \%$ and finally $25 \%$ of that level. The fungal strains used were adjusted to $1 \times 10^{8}, 1 \times 10^{6}$, and $1 \times 10^{4}$ conidia $\mathrm{ml}^{-1}$. The combinations of those insecticides with $B$. bassiana (LPSc 1067, LPSc 1082) and M. anisopliae (LPSc 907) caused higher mortality to $R$. bergi nymphs than
\end{abstract}

Handling Editor: Nicolai Meyling.

S. A. Pelizza $(\bowtie) \cdot$ M. N. Fogel · C. E. Lange

Centro de Estudios Parasitológicos y de Vectores

(CEPAVE), CCT La Plata-CONICET-UNLP, Boulevard

120 s/n e/ 61 y 62, 1900 La Plata, Argentina

e-mail: pelizza@cepave.edu.ar

\section{S. A. Pelizza - A. C. Scorsetti - M. N. Cabello}

Instituto de Botánica Carlos Spegazzini (FCNyM-UNLP), Calle 53 \# 477, 1900 La Plata, Argentina

S. G. Pacheco-Marino

Instituto de Genética Veterinaria Ingeniero Fernando Noel Dulout (IGEVET), CCT La Plata-CONICET, La Plata,

Argentina any of the individual agents used alone. The three insecticides tested did not affect the isolates of the two species of entomopathogenic fungi employed. In conclusion, the use of these biorational insecticides in an IPM program aimed at control of the grasshopper $R$. bergi could be of value.

Keywords Grasshoppers · Interactions · Metarhizium anisopliae - Beauveria bassiana . Pesticides · Orthoptera: Acrididae

\section{Introduction}

As in other temperate grasslands of the world, throughout the Argentine Pampas and parts of Patagonia grasshoppers are among the most economically

\author{
S. A. Stenglein \\ Laboratorio de Biología Funcional Y Biotecnología \\ (BIOLAB)-CICBA-INBIOTEC, Facultad de Agronomía \\ de Azul, UNCPBA, Republica de Italia \# 780, 7300 Azul, \\ Argentina \\ M. N. Cabello - C. E. Lange \\ Comisión de Investigaciones Científicas (CIC) de la \\ Provincia de Buenos Aires, La Plata, Argentina
}


significant invertebrate native herbivores (Mariottini et al. 2011). Ronderosia bergi (Orthoptera: Acrididae) (Stål), the melanopline grasshopper selected for this study is characterized by no obligatory embryonic diapause. This is one of 18 species found in natural grasslands that affects certain crops in areas of central and northern Argentina and is thus considered economically relevant (Mariottini et al. 2010). To date, chemical insecticides are the only available option for grasshopper control in Argentina, but the use of such chemical agents is of serious environmental concern (Gonzalez et al. 2010). A recognition of the drawbacks associated with insecticide use-such as non-target effects, environmental pollution, and high economic costs-have prompted the development of alternative control strategies and environmentally less harmful chemicals such as insect-growth regulators. Those types of pesticides have a relatively minor detrimental effect on the environment and the other inhabitants therein (Horowitz and Ishaaya 2004).

The different problems caused by the conventional chemical insecticides have led to the application of alternative methods such as the use of entomopathogens. Among these, control agents based on fungi have attracted much attention as biological pesticides. Beauveria bassiana (Bals.-Criv) Vuillemin, and Metarhizium anisopliae (Metschn.) Sorokin (Ascomycota: Hypocreales) are two of the most common species of entomopathogenic fungi that have been investigated, with both offering promise in the microbial control of certain crop pests (Jaronski 2010).

A criticism raised in relation to the use of entomopathogenic fungi as biocontrol agents, however, is that the microbial action is too slow (Lomer et al. 2001). The alternative use of chemical insecticides-ideally at low, sublethal levels-in combination with entomopathogenic fungi has developed as an attractive approach to circumvent this difficulty (Bitsadze et al. 2013). Indeed, even though insects killed by entomopathogenic fungi often take longer to die than those treated with chemical pesticides, the damage to crops decrease during the disease incubation period since the infected insects tend to eat less than healthy ones, modify their survival and their reproductive potential (Moore et al. 1992; Pelizza et al. 2013).

Previous investigations have demonstrated that sublethal doses of insecticides can increase stress, compromise the immune system, and alter insect behavior so as to lead to an improved effectiveness of the fungal pathogen (Quintela et al. 2013). The utilization of appropriately selected insecticides in association with entomopathogenic fungi can increase the efficiency of pest control, allowing a consequent reduction in the amount of the chemical that is applied along with a minimization of environmental contamination and the expression of pest resistance (Oliveira et al. 2003; Paula et al. 2011). Earlier reports have suggested that Dimilin ${ }^{\mathrm{TM}}$ (Uniroyal Chemical Co., Inc), a chitin-synthesis inhibitor containing the active ingredient diflubenzuron, makes infection by hypocrealean entomopathogens faster and easier. Consequently, Hassan and Charnley (1989) found that the cuticle of Manduca sexta treated with that agent exhibited a diminished resistance to invasion by the hyphae of M. anisopliae. In vitro assays performed by Reuter et al. (1996) furthermore demonstrated that an admixture of diflubenzuron and B. bassiana increased the percent mortality of a North-American grasshopper species. Similar results were reported by Foster et al. (1996) when a natural population was exposed to the same mixture under field conditions.

Since grasshoppers in general are susceptible to infection by entomopathogenic fungi, the compatibility of chemical insecticides with the fungi B. bassiana and $M$. anisopliae in the control of $R$. bergi is a consideration of major relevance in the development of an integrated pest-management (IPM) strategy for the protection of vulnerable crops (Horowitz and Ishaaya 2004). In this article, we evaluated the interactions between three insecticides of which two are considered biorational and three strains of entomopathogenic fungi, under laboratory conditions in order to determine the possible usefulness of combinations of these agents against the pest grasshopper $R$. bergi.

\section{Materials and methods}

\section{Insect colony}

Adult males and females of $R$. bergi were collected with insect nets in grasslands at Pereyra Iraola Provincial Park $\left(34^{\circ} 86^{\prime} 56^{\prime \prime} \mathrm{S}, 58^{\circ} 06^{\prime} 68^{\prime \prime} \mathrm{W}\right)$, Berazategui county, Buenos Aires province Argentina. Once in the laboratory, the grasshoppers were maintained following the general procedures described by Henry (1985). Individuals of both sexes were placed in wirescreened, aluminum cages $(20 \times 20 \times 30 \mathrm{~cm})$ in a 
rearing room under the controlled conditions used worldwide $\left(30{ }^{\circ} \mathrm{C}, 14: 10 \mathrm{~L}: \mathrm{D}\right.$ period, $40 \% \mathrm{RH}$; Mariottini et al. 2010). The grasshoppers were fed daily with thoroughly washed fresh leaves of a variety of grasses, lettuce, cabbage, and wheat-bran flakes. Each cage was provided with substrates for egg-pod laying that consisted of plastic containers $(10 \mathrm{~cm}$ deep) filled with sterilized sand. Thermoregulation and mating was stimulated by the use of $75-\mathrm{W}$ bulbs suspended $15 \mathrm{~cm}$ above each cage. The grasshoppers were maintained until death, at which point they were immediately examined upon dissection (Lange 1996) or else incubated in humid chambers (Lacey and Brooks 1997) to check for their health status. The nymphs emerging from the resulting egg-pods were used in the laboratory assays.

Insecticides and fungal strains

The synthetic chemical pesticide Coragen ${ }^{\mathrm{TM}}$ [rynaxypyr $20 \%$ (w/v), DuPont S.A., Argentina] and two biorational chemical insecticides Match ${ }^{\mathrm{TM}}$ [luphenuron $5 \%$ (w/v), Sygenta S.A., Argentina] and Intrepid ${ }^{\mathrm{TM}}$ [methoxyfenozide $24 \%(\mathrm{w} / \mathrm{v})$, Dow AgroSciences S.A., Argentina] were used in these experiments. Rynaxypyr acts as an activator of the ryanodine receptors of insects to undermine the process of muscle contraction. Affected individuals suffer paralysis and quickly stop feeding. Luphenuron acts by inhibiting the growth of insects and interfering with chitin synthesis. Methoxyfenozide acts on the growth hormone of insects to accelerate molting. The insecticides were tested at three concentrations: the average concentration recommended for application in the field on soybean $(100 \%), 50 \%$ of this level, and finally $25 \%$ to give levels of 60,30 , and $15 \mathrm{ppm}\left(\mathrm{mg}\right.$ a.i. $\left.\mathrm{l}^{-1}\right)$ for rynaxypyr; 100,50 , and $25 \mathrm{ppm}\left(\mathrm{mg}\right.$ a.i. $\left.\mathrm{l}^{-1}\right)$ for luphenuron; and 144, 72, and $36 \mathrm{ppm}\left(\mathrm{mg}\right.$ a.i. $\mathrm{l}^{-1}$ ) for methoxyfenozide (CASAFE 2013).

The fungal strains used were the SpegazziniInstitute-culture-collection LPSc 1067 and LPSc 1082 of B. bassiana, and strain LPSc 907 of $M$. anisopliae. All isolates were preserved by lyophilization. Morphological species identification was corroborated by extracting the DNA of the monosporic cultures according to Stenglein and Balatti (2006). PCRs were carried out in an XP thermal cycler (Bioer Technology Co, Hangzhou, China) to amplify and sequence the ITS rDNA region of $B$. bassiana using primer pairs ITS5/ITS4 (Rehner and Buckley 2005) and the translation elongation factor 1-alpha (EF intron region) of $M$. anisopliae using primer pairs EF1T/EF2T (Bischoff et al. 2009). Fragments similarities with previously published sequence data were examined with BLASTn (Altschul et al. 1990) in the NCBI web page. The sequences generated in this study were submitted to GenBank (accession numbers KF500409 and KJ7722495 for B. bassiana LPSc 1067, LPSc 1082, respectively; KJ772494 for $M$. anisopliae LPSc 907).

The choice of these fungal strains was based on their laboratory efficacy against other pest grasshopper and locust species from Argentina (Pelizza et al. 2012a, b). Conidia of the fungal strains were obtained from cultures on potato-dextrose-agar medium (Britania S.A., Buenos Aires, Argentina) after incubation for ten days at $25{ }^{\circ} \mathrm{C}$ in the dark. Afterward, the conidia were harvested with disposable cell scrapers (Fisherbrand $^{\mathrm{TM}}$ ) and placed in test tubes containing $0.01 \%$ $(\mathrm{v} / \mathrm{v})$ polyoxyethylene sorbitan monolaurate (Tween $80^{\mathrm{TM}}$; Merck). Suspensions were vortexed for $2 \mathrm{~min}$, filtered through four layers of sterile muslin, and adjusted

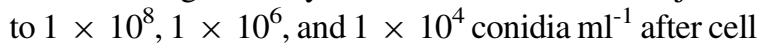
counting in a Neubauer hemocytometer. The viability of the conidia from each isolate and the concentrations used in the tests were determined after $24 \mathrm{~h}$ as described by Lane et al. (1988). This germination test was repeated for each stock suspension to maintain the constancy of the viability assessments. In all cases, the average viability of the conidia was over $95 \%$.

Compatibility in vitro of fungal isolates

with chemical insecticides

In vitro compatibility between isolates of $B$. bassiana (LPSc 1067, LPSc 1082) or M. anisopliae (LPSc 907) and the three insecticides commonly used for pest control was studied at the three insecticide concentrations cited above along with the highest concentration of each of the fungal strains (i.e., $1 \times 10^{8}$ conidia $\mathrm{ml}^{-1}$ ). An admixture of $1 \mathrm{ml}$ of fungal suspension plus $1 \mathrm{ml}$ of each chemical concentration was performed to give a final volume of $2 \mathrm{ml}$. After $1 \mathrm{~h}, 0.5 \mathrm{ml}$ of each mixture was spread over three Petri dishes containing water-agar medium. The dishes were then incubated at $25^{\circ} \mathrm{C}$ for a 12 -h photoperiod and the percentage of germinated conidia quantified $24 \mathrm{~h}$ later. A control without the addition of chemical insecticide was made 
for each fungal isolate. The data were analysed using the Wald statistics (Generalized Linear Model) with the Genmod procedure with the software SAS/STAT ${ }^{\circledR}$ Version 8 (2001), with a binomial error distribution and a logit link function. Differences between treatments were detected using a posteriori Fisher LSD test with Statistica 7 software.

\section{Experimental inoculations}

Experimental inoculations per os were conducted on third-instar nymphs of $R$. bergi in order to determine the percent mortality at each concentration of the insecticide and different densities of the three fungal strains. We chose this inoculation technique on the basis of its recommendation by the manufacturer of all three of the chemical insecticides. Twenty-four hours before the beginning of the experiment, the nymphs were placed individually in $20 \mathrm{ml}$ foam-plugged glass vials and left without food. Lettuce disks (5 $\mathrm{mm}$ in diameter) submerged in desired concentrations of fungi and insecticides were given to treated groups according to Inglis et al. (1996). Control groups were fed with lettuce disks submerged in $1 \mathrm{ml}$ of $0.01 \%(\mathrm{v} / \mathrm{v})$ Tween $80^{\mathrm{TM}}$ only. Under each experimental condition ten thirdinstar nymphs were processed in triplicate for both the treated and control insects. Immediately after feeding, the treated and control nymphs were placed in acetate tubes $(50 \times 9-\mathrm{cm})$, in groups of ten individuals, and fed with lettuce, cabbage, and wheat bran. Both the treated and control insects were maintained at $30{ }^{\circ} \mathrm{C}, 60 \%$ $\mathrm{RH}$, and a 14:10 L:D photoperiod. The cumulative mortality was recorded daily for ten days. Dead grasshoppers with no external mycelium were surface-sterilized by dipping them successively in $70 \%$ ethanol (10-15 s), $0.5 \%$ sodium hypochlorite solution ( $1 \mathrm{~min}$ ), and sterile distilled water (1 min, two consecutive baths) according to Lacey and Brooks (1997). Next, they were placed in a sterile culture chamber consisting of a Petri dish $(60 \mathrm{~mm}$ diameter $)$ with a filter-paper disk that was periodically moistened with sterile distilled water and incubated at $25{ }^{\circ} \mathrm{C}$ in the dark, for 35 days to allow fungal development. Mycosis was confirmed by microscopical examination of the dead grasshoppers. When the mortality in the treated grasshoppers at different concentrations $\left(1 \times 10^{8}\right.$,

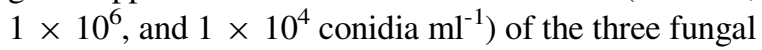
strains and different chemical compounds $(60,30$, and $15 \mathrm{ppm}$ for rynaxypyr; 100, 50, and $25 \mathrm{ppm}$ for luphenuron; and 144, 72, and 36 ppm for methoxyfenozide) was $50 \%$ or higher, the median survival time (MST) was calculated based on Kaplan-Meier estimate of the survival distribution function (Xlstat life software 2014). Pairwise comparisons between survival curves were made by log-rank test. Moreover, when the mortality was $50 \%$ or higher in the grasshoppers treated with the different chemical compounds alone, the following lethal and sublethal-toxicity parameters were calculated (DEBtox v. 2.0.1 program; Péry et al. 2002; Jager et al. 2006): the median lethal concentration $\left(\mathrm{LC}_{50}\right)$, the concentration lethal to $10 \%$ of the exposed individuals $\left(\mathrm{LC}_{10}\right)$, the non-effect concentration (NEC). Significant differences between the percent mortalities after a ten-day exposure to the different treatments were analysed and a posteriori test of linear contrast led us to measure the significance among combinations using the Wald statistics (Generalized Linear Model) with the Genmod procedure with the software SAS/STAT ${ }^{\circledR}$ Version 8 (2001), with a binomial error distribution and a logit link function.

Interaction between entomopathogenic fungi and chemical insecticides against $R$. bergi

The interaction of B. bassiana (LPSc 1067, LPSc 1082) and M. anisopliae (LPSc 907) with the insecticides rynaxypyr, luphenuron, and methoxyfenozide against $R$. bergi grasshoppers was investigated in the following manner. Of each fungal suspension and each insecticide solution, $5 \mathrm{ml}$ were combined, to give a final volume of $10 \mathrm{ml}$ (these were adjusted to reach the above mentioned concentration for each fungal strain and chemical insecticide evaluated). Suspensions were homogenized by vortexing for $2 \mathrm{~min}$. A lettuce disk (diameter, $5 \mathrm{~mm}$ ) was submerged in each mixture. The experimental design and inoculation techniques was performed as indicated in the previous section. The cumulative mortality was recorded daily for ten days and mycosis confirmed by microscopical examination of the dead grasshoppers. When mortality was $50 \%$ or higher, the toxicologic effect of rynaxypyr, luphenuron, and methoxyfenozide on third-instar $R$. bergi nymphs was calculated. The $\mathrm{LC}_{10}-\mathrm{LC}_{50}$ and NEC values were expressed as ppm, and the MST in days, both parameters along with the respective standard deviations (SD). Analysis for additive, antagonistic, or synergistic interaction was based on a binomial test and comparison of the expected and observed percentage mortality 
according to Nishimatsu and Jackson (1998). Expected mortality at a set concentration of insecticide and fungal strain was based on the formula $\mathrm{P}_{\mathrm{e}}=\mathrm{P}_{\mathrm{o}}+\left(1-\mathrm{P}_{\mathrm{o}}\right)$ $\left(\mathrm{P}_{1}\right)+\left(1-\mathrm{P}_{\mathrm{o}}\right) \quad\left(1-\mathrm{P}_{1}\right) \quad\left(\mathrm{P}_{2}\right)$, where $\mathrm{P}_{\mathrm{e}}$ is the expected mortality on combination of the two insecticidal agents, $\mathrm{P}_{\mathrm{o}}$ is the natural (control) mortality, $\mathrm{P}_{1}$ is the mortality after treatment with the insecticide alone, and $\mathrm{P}_{2}$ is the mortality after treatment with the fungal strain alone. Additivity was indicated if $\chi^{2}<3.84$. Antagonism was indicated if $\chi^{2}>3.84$ and $\mathrm{P}_{\mathrm{c}}<\mathrm{P}_{\mathrm{e}}$, where $P_{c}$ is the observed mortality of the insecticide and fungal strain combination and $\mathrm{P}_{\mathrm{e}}$ is the expected mortality of the combination. Synergism was indicated if $\chi^{2}>3.84$ and $\mathrm{P}_{\mathrm{c}}>\mathrm{P}_{\mathrm{e}}$.

\section{Results}

We observed significant differences (Table 1) in the in vitro viability of the fungal conidia in the presence of the three chemical insecticides, however the percent of germination was not affected negatively, suggesting compatibility between these two different control agents (Table 2). When we compared the percent mortality of third-instar $R$. bergi nymphs registered after a ten-day exposure, significant differences were found with the chemical insecticides at their maximum recommended field concentration (100\%) and at the reduced concentration $(25 \%)$ (Table 3$)$. In addition, the percent mortality obtained after exposure of the nymphs to the fungal strain alone was higher than those with the insecticides alone at those same maximum concentrations $\left(\chi^{2}=140.63, d f=2, \quad P<0.0001\right)$. Moreover, the combined treatment with strains LPSc 907, LPSc 1082 or LPSc 1067 and the compounds produced $100 \%$ mortality in the nymphs, except for the combination of luphenuron with strain LPSc 1067, where the mortality was $80 \%$ (Fig. 1a). At $50 \%$ of the maximum concentrations of both the chemical insecticides and the fungal isolates, we also observed an increase in the mortality of the R. bergi nymphs after exposure to the two agents in combination compared to treatments with those compounds or the fungi alone $\left(\chi^{2}=160.42, d f=2\right.$, $P<0.0001)$, except for the combination luphenuronLPSc $1067(66.6 \% \pm 0.7)$ that was lower than fungus control $(73.3 \% \pm 0.82)\left(\chi^{2}=45.97, d f=2\right.$, $P<0.0001)$. The percent mortalities caused by the all fungal strains (M. anisopliae LPSc 907, B. bassiana LPSc 1067 and LPSc 1082) were higher than the values recorded for any of the chemicals alone and significant differences between fungal strains were found (Fig. 1b; Table 3). At $25 \%$ of maximum concentrations we observed significant differences in the percent mortalities of fungal strains, chemicals insecticide and the combination between both (Table 3 ). The chemicals and fungal strains showed additive effect when combined, except the combination rynaxypir-LPSc 1067 and rynaxypyr-LPSc 907 that showed synergism (Table 4). Also, we observed that the combination rynaxypyr-LPSc 907 produced the highest mortality. In addition, LPSc 1067 and LPSc 1082 gave rise to their higher percent mortalities in combination with rynaxypyr $\left(\chi^{2}=128.62, d f=2, P<0.0001\right)$ and luphenuron $\left(\chi^{2}=49.93, d f=2, P<0.0001\right)$ respectively (Fig. 1c).

Table 4 shows the toxicological parameter $\left(\mathrm{LC}_{50}\right)$ determined after a ten-day exposure to each pesticide alone and in combination with the various fungal strains. Rynaxypyr alone $\left(\mathrm{LC}_{50}=39.5 \mathrm{ppm}\right)$ was the chemical with the highest value, whereas methoxyfenozide showed the lowest $\left(\mathrm{LC}_{50}=171 \mathrm{ppm}\right)$. In all instances a lower $\mathrm{LC}_{50}$ was obtained when combining any of the three pesticides with the different fungal isolates (Table 4). At maximum field concentrations, we observed an additive effect in all combinations. At $50 \%$ concentration we observed synergism in the combinations rynaxypir-LPSc1082-LPSc907,

Table 1 Results of the Generalized Linear Model on the effects of the chemical insecticides rynaxypyr, luphenuron and methoxyfenozide on the percent germination of Beauveria bassiana (strains LPSc 1067, LPSc 1082) and Metarhizium anisopliae (strain LPSc 907) conidia

\begin{tabular}{|c|c|c|c|c|c|c|c|c|c|}
\hline \multirow[t]{2}{*}{ Dose } & \multicolumn{3}{|c|}{$100 \%$} & \multicolumn{3}{|c|}{$50 \%$} & \multicolumn{3}{|c|}{$25 \%$} \\
\hline & df & $\chi^{2}$ & $P$ value & $\mathrm{df}$ & $\chi^{2}$ & $P$ value & $\mathrm{df}$ & $\chi^{2}$ & $P$ value \\
\hline Insecticides & 3 & 156.08 & $<0.0001$ & 3 & 101.93 & $<0.0001$ & 3 & 143.84 & $<0.0001$ \\
\hline Strains & 2 & 222.98 & $<0.0001$ & 2 & 316.87 & $<0.0001$ & 2 & 344.98 & $<0.0001$ \\
\hline Insecticides $\times$ strains & 6 & 163.32 & $<0.0001$ & 6 & 24.37 & 0.0004 & 6 & 172.84 & $<0.0001$ \\
\hline
\end{tabular}


luphenuron-LPSc1082-LPSc907, and methoxyfenozide-LPSc 907, while in the other combinations we observed an additive effect. Finally, at $25 \%$ concentration of the pesticides we observed only a synergism effect with the combinations rynaxypyr-LPSc907LPSc1067, while in all other combinations the effect was additive (Table 4). Furthermore, we found similar values for the $\mathrm{LC}_{10}$ and NEC sublethal toxicological parameters: those values were 27.5 and $25.1 \mathrm{ppm}$, respectively, for rynaxypyr; 100 and $100 \mathrm{ppm}$ for luphenuron; and 58.0 and $36.0 \mathrm{ppm}$ for methoxyfenozide.

The MST calculated for the strains, the chemicals and their combinations at $100 \%$ concentration showed that the most virulent combinations were luphenuronLPSc 1082 and rynaxypyr-LPSc 1067 with MST of 1.8 and 1.9 days respectively, which were significantly different than the rest of the treatments (log-rank test, $P<0.05)$. On the other hand, the highest MST were observed in the strain LPSc1082 (5.4 days) and in combination with methoxyfenozide (5.7 days), being significantly different than the rest of the treatments (log-rank test, $P<0.05$ ). At $50 \%$ concentration, the lowest MST was 3.6 days, observed in the treatments rynaxypyr-LPSc 907 and luphenuron-LPSc 1082, which were significantly different than the other treatments (log-rank test, $P<0.05$ ). As observed for the $100 \%$ concentration, the treatments LPSc1082 and in combination with methoxyfenozide have MST significantly higher than the rest of the treatments (log-rank test, $P<0.05$ ). At $25 \%$ concentration the MST were in general high and similar among treatments, only the combination rynaxypyr-LPSc 907 have a significantly lower MST compared with the rest of the treatments (log-rank test, $P<0.05$ ) (Table 5).

\section{Discussion}

Combination of sublethal concentrations of chemical insecticides and entomopathogenic fungi can cause increased stress, immunocompromise, and a consequent alteration in insect physiology and behavior, thus leading to an improved of performance in an insect-control program that include a biological component (Boucias et al. 1996). A pairing of sublethal concentrations of insecticides with fungal entomopathogens can increase pest mortality as well as reduce the killing time in comparison with either agent alone 
Table 3 Results of the Generalized Linear Model on the percent mortality of third-instar Ronderosia bergi nymphs after ten-day exposure at different concentrations of biorational pesticides alone and in combination with the Beauveria bassiana LPSc 1067, LPSc 1082, and Metarhizium anisopliae LPSc 907 strains

\begin{tabular}{|c|c|c|c|c|c|c|c|c|c|}
\hline \multirow[t]{2}{*}{ Dose } & \multicolumn{3}{|c|}{$100 \%$} & \multicolumn{3}{|c|}{$50 \%$} & \multicolumn{3}{|c|}{$25 \%$} \\
\hline & $\mathrm{df}$ & $\chi^{2}$ & $P$ value & df & $\chi^{2}$ & $P$ value & df & $\chi^{2}$ & $P$ value \\
\hline Insecticides & 3 & 275.82 & $<0.0001$ & 3 & 0.00 & 1 & 3 & 40.28 & $<0.0001$ \\
\hline Strains & 2 & 934.18 & $<0.0001$ & 2 & 10872.7 & $<0.0001$ & 2 & 18.93 & 0.0003 \\
\hline Insecticides $\times$ strains & 6 & 137.32 & $<0.0001$ & 6 & 13299.0 & $<0.0001$ & 6 & 43.59 & $<0.0001$ \\
\hline
\end{tabular}

(Paula et al. 2011). Although studies on the joint action of chemical insecticides and entomopathogenic fungi have been carried out on the binary management of the locust (Bitsadze et al. 2013), similar investigations on other grasshopper pests, such as $R$. bergi, have been scant.

Variations in the effect of the two entomopathogenic fungi $B$. bassiana and $M$. anisopliae on the insect toxicity of chemical insecticides - ranging from antagonistic to neutral to synergistic-have been reported (Quintela et al. 2013; Bitsadze et al. 2013). In the present work, although the three different insecticides utilized exhibited varying effects (synergistic or additive) with respect to toxicity against $R$. bergi when combined with strains from either $B$. bassiana or $M$. anisopliae, we never observed an antagonism effect between them. On the basis of these observations, the combinations of those insecticides with B. bassiana (LPSc 1067, LPSc 1082) and $M$. anisopliae (LPSc 907) were more toxic to $R$. bergi nymphs than either of the individual agents used alone.

The three insecticides tested (rynaxypyr, luphenuron, methoxyfenozide) did not affect the isolates of the two species of entomopathogenic fungi employed. Recent studies have indicated that various oil-based surfactants may impact on the viability and virulence of fungal entomopathogens in several ways (Mascarin et al. 2014). Anderson and Roberts (1983) pointed out that the formulation of an insecticide is just as significant as the active ingredient and in certain instances may increase the number of entomopathogenic-fungal colonies. Moino and Alves (1998) suggested two possible explanations for these results: First, the fungi-as a physiologic mechanism of resistance-could metabolize the insecticides and liberate compounds that can be used by them as secondary nutrients. Second, within a toxic environment, the fungus could respond with an enhanced reproductive effort in the form of an increased conidia production. Another possible explanation is that toxicologically inert substances present in the insecticide formulations could be used directly as nutrients so as to increase the vegetative growth and conidia production of the pathogen (Neves et al. 2001).

Compatibility studies in vitro between insecticides and entomopathogenic fungi have the advantage of exposing the pathogen to the maximum action of the compounds, a condition that often does not occur under field conditions. Thus, compatibility in vitro with an insecticide is strong evidence in favour of the utility of that combination under field conditions (Alves et al. 1998). Oliveira et al. (2003) reported that formulations of insecticides based on triazophos, chlorpyrifos, and endosulfan inhibited the viability of $B$. bassiana conidia $100 \%$ at the three concentrations used. Moreover, they ascertained that conidia germination in the presence of commercial pesticides in vitro was one of the most informative indicators of compatibility in the field.

Different interactions between fungal strains and chemicals on field applications have been observed by different authors. Previous field applications against grasshoppers in the United States (Foster et al. 1996) demonstrated that a B. bassiana-Dimi$\operatorname{lin}^{\mathrm{TM}}$ combination was more effective than the combination B. bassiana with other chemical agents. Delgado et al. (1999) observed in populations of grasshoppers in Mali treated with a mixture of $B$. bassiana and Dimilin ${ }^{\mathrm{TM}}$ that the decrease in the insects populations continued until the end of the monitoring effort. Thus, when an IPM strategy is devised, the compatibility of products sprayed on the crop must be taken into account in order to avoid the use of the most toxic compounds (van Driesche et al. 2007).

In general, the use of the insecticides rynaxypyr, luphenuron, and methoxyfenozide in the formulations 
Fig. 1 Mean percent \pm SD mortality of Ronderosia bergi exposed to chemical insecticides and entomopathogenic fungi both alone and in combination at a maximum field concentration $(100 \%)$ and at concentrations of the chemical agents and fungal strains reduced to b $50 \%$ and $\mathbf{c} 25 \%$
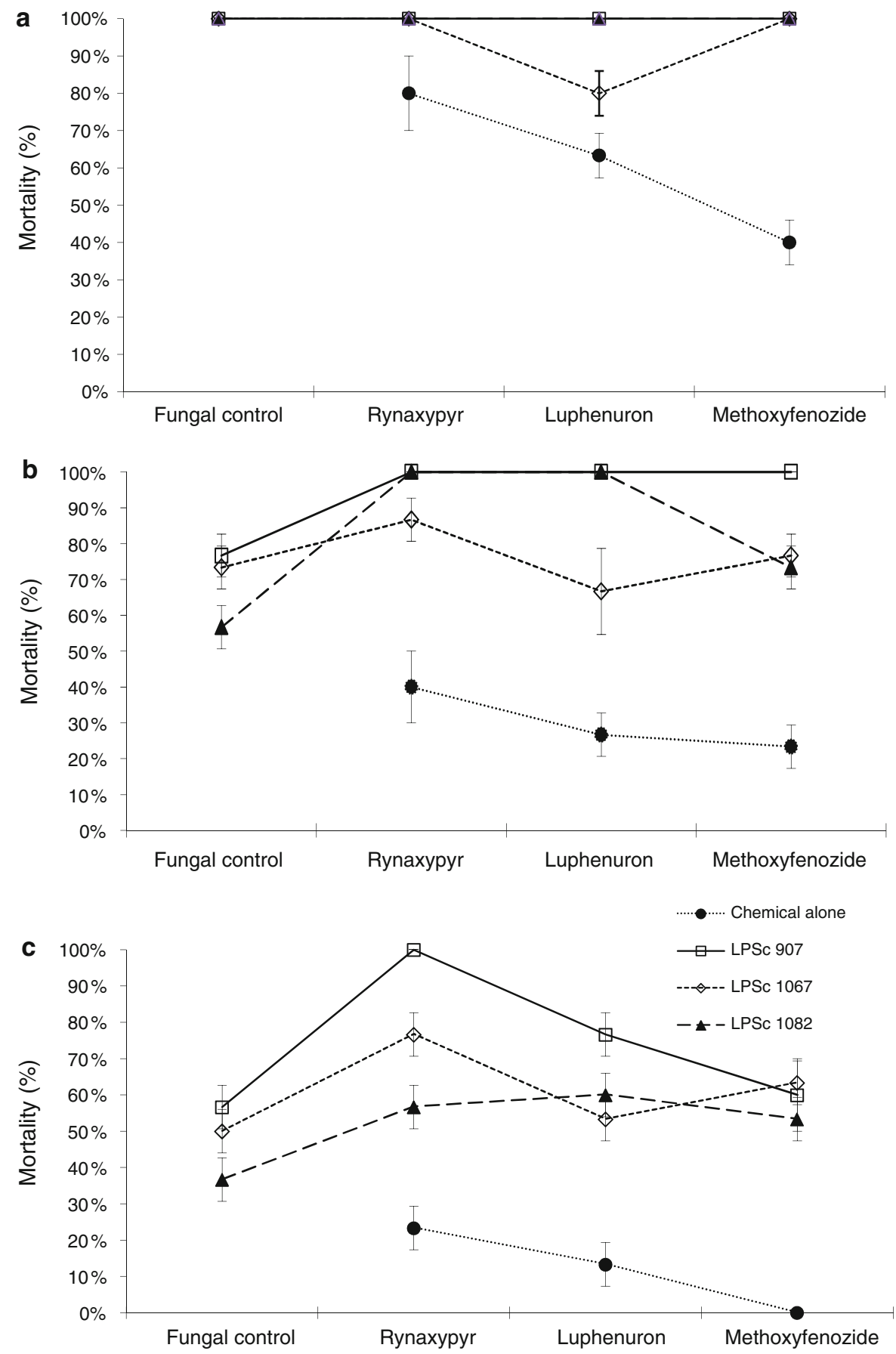

and at the concentrations tested here failed to have an adverse effect on the conidial viability of $B$. bassiana (LPSc 1067, LPSc 1082) and M. anisopliae (LPSc 907). Furthermore, when comparing the mortality caused by these three insecticides alone and in combination with different fungal isolates, for each of those compounds we observed a similar percent mortality with $R$. bergi nymphs, even at a $50 \%$ reduction in the recommended field dose. Our results revealed that the different combinations between chemical insecticides and fungal strains showed synergistic and additive effects but not antagonism. 
Table 4 Median lethal concentrations (LC50) of rynaxypyr, luphenuron, and methoxyfenozide alone and in combination with the entomopathogenic fungal strains LPSc 907, LPSc 1067, and LPSc 1082 against Ronderosia bergi after a ten-day exposure

\begin{tabular}{|c|c|c|c|c|c|c|c|c|c|}
\hline & \multicolumn{3}{|c|}{ Field dose $(100 \%)$} & \multicolumn{3}{|l|}{$50 \%$} & \multicolumn{3}{|l|}{$25 \%$} \\
\hline & $\mathrm{LC}_{50}$ & SD & $\chi^{2}$ (response) & $\mathrm{LC}_{50}$ & SD & $\chi^{2}$ (response) & $\mathrm{LC}_{50}$ & SD & $\chi^{2}$ (response) \\
\hline Rynaxypyr & 39.5 & 3 & - & 70.4 & 48.8 & - & 75.7 & - & - \\
\hline Rynaxypyr + 1067 & 12.4 & 1.82 & 0.00 (additive) & 9.74 & 3.48 & 0.03 (additive) & 8.09 & 1.81 & 3.85 (synergistic) \\
\hline Rynaxypyr + 1082 & 11.7 & 2.26 & 0.00 (additive) & 12.6 & 2.63 & 10.56 (synergistic) & 14.7 & 6.55 & 0.37 (additive) \\
\hline Rynaxypyr + 907 & 5.46 & 1.18 & 0.00 (additive) & 4.97 & 1.03 & 4.87 (synergistic) & 4.72 & 1.4 & 14.97 (synergistic) \\
\hline Luphenuron & 100 & 3.96 & - & 203 & 243 & - & 25 & 0.846 & - \\
\hline Luphenuron + 1067 & 32.1 & 4.6 & 1.20 (additive) & 28.3 & 3.74 & 3.32 (additive) & 23.6 & 3.65 & 0.08 (additive) \\
\hline Luphenuron + 1082 & 21.8 & 1.96 & 0.00 (additive) & 21.6 & 2.48 & 14.05 (synergistic) & 25 & 0.0092 & 2.72 (additive) \\
\hline Luphenuron +907 & 14.1 & 3.59 & 0.00 (additive) & 14.4 & 4.56 & 9.16 (synergistic) & 20.1 & 12.5 & 2.60 (additive) \\
\hline Methoxyfenozide & 171 & 32.4 & - & 72 & 0.98 & - & - & - & - \\
\hline Methoxyfenozide +1067 & 33.1 & 5.16 & 0.00 (additive) & 33.8 & 5.93 & 0.15 (additive) & 36 & 0.0086 & 3.37 (additive) \\
\hline Methoxyfenozide +1082 & 40.4 & 5.86 & 0.00 (additive) & 37.5 & 5.97 & 0.58 (additive) & 34.1 & 6.75 & 3.61 (additive) \\
\hline Methoxyfenozide +907 & 22.2 & 5.63 & 0.00 (additive) & 25.2 & 6.41 & 6.58 (synergistic) & 29.3 & 13.6 & 0.14 (additive) \\
\hline
\end{tabular}

The number of dead grasshoppers observed, and the number of dead grashoppers expected was used to test the hypothesis of independence with $1 \mathrm{df}$ and $P=0.05$. Additivity was indicated if $\chi^{2}<3.84$. Antagonism was indicated if $\chi^{2}>3.84$ and $\mathrm{P}_{\mathrm{c}}<\mathrm{P}_{\mathrm{e}}$, where $P_{c}$ is the observed mortality of the insecticide and fungal strain combination and $P_{e}$ is the expected mortality of the combination. Synergism was indicated if $\chi^{2}>3.84$ and $\mathrm{P}_{\mathrm{c}}>\mathrm{P}_{\mathrm{e}}$

Table 5 Median survival time in days (mean $\pm \mathrm{SD}$ ) at different concentrations of fungi and pesticides alone and in combination with the Beauveria bassiana LPSc 1067, LPSc 1082 and Metarhizium anisopliae LPSc 907strains

Different letters denote significant differences between treatments in the same column according to the log-rank test $(P<0.05)$

\begin{tabular}{|c|c|c|c|}
\hline \multirow[t]{2}{*}{ Treatments } & \multicolumn{3}{|l|}{ Dose } \\
\hline & $100 \%$ & $50 \%$ & $25 \%$ \\
\hline LPSc 907 & $3.45 \pm 0.34 \mathrm{ab}$ & $6.5 \pm 0.61 \mathrm{ag}$ & $8 \pm 0.37 \mathrm{a}$ \\
\hline LPSc 907 + Rynaxypyr & $2.7 \pm 0.26 \mathrm{a}$ & $3.6 \pm 0.34 b$ & $5.6 \pm 0.52 b$ \\
\hline LPSc 907 + Luphenuron & $2.9 \pm 0.30 \mathrm{a}$ & $4.8 \pm 0.45 \mathrm{cdh}$ & $6.5 \pm 0.51 b c$ \\
\hline LPSc 907 + Methoxyfenozide & $3.6 \pm 0.37 \mathrm{ab}$ & $4.3 \pm 0.44 \mathrm{ce}$ & $6.9 \pm 0.47 \mathrm{ac}$ \\
\hline LPSc 1082 & $5.4 \pm 0.53 \mathrm{c}$ & $8 \pm 0.46 a$ & - \\
\hline LPSc 1082 + Rynaxypyr & $3.2 \pm 0.31 \mathrm{ad}$ & $5.5 \pm 0.55 \mathrm{df}$ & $7.2 \pm 0.57 \mathrm{ac}$ \\
\hline LPSc 1082 + Luphenuron & $1.8 \pm 0.13 \mathrm{e}$ & $3.6 \pm 0.36 \mathrm{be}$ & $6.6 \pm 0.48 \mathrm{ac}$ \\
\hline LPSc 1082 + Methoxyfenozide & $5.7 \pm 0.59 \mathrm{c}$ & $7.4 \pm 0.5 \mathrm{a}$ & $8.4 \pm 0.46 \mathrm{a}$ \\
\hline LPSc 1067 & $4 \pm 0.32 \mathrm{bdfg}$ & $6.6 \pm 0.58 \mathrm{af}$ & - \\
\hline LPSc 1067 + Rynaxypyr & $1.9 \pm 0.15 \mathrm{e}$ & $5.5 \pm 0.6 f g h$ & $7.3 \pm 0.49 \mathrm{ac}$ \\
\hline LPSc 1067 + Luphenuron & $3 \pm 0.27 \mathrm{af}$ & $6.3 \pm 0.45 \mathrm{af}$ & $8.4 \pm 0.4 \mathrm{a}$ \\
\hline LPSc 1067 + Methoxyfenozide & $3.5 \pm 0.39 \mathrm{af}$ & $5.4 \pm 0.53 \mathrm{gdf}$ & $7.7 \pm 0.47 \mathrm{ac}$ \\
\hline Rynaxypyr & $4 \pm 0.4 \mathrm{bdfg}$ & - & - \\
\hline Luphenuron & $5 \pm 0.4 \mathrm{cg}$ & - & - \\
\hline Methoxifenozide & - & - & - \\
\hline
\end{tabular}

Further field studies with these chemical insecticides and entomopathogenic fungi applied as a mixture can provide additional information on the insect toxicity by these combinations as well as their effectiveness against
$R$. bergi under natural conditions. Such biorational insecticides could conceivably reduce concentrations of chemical compounds to the benefit of the farmer and the environment. 
Acknowledgments This study was partially supported by Consejo Nacional de Investigaciones Científicas y Tecnológicas (PIP 0009), Comisión de Investigaciones Científicas de la provincia de Buenos Aires (CICPBA), and Universidad Nacional de La Plata (UNLP, 11/N 651). Marta Cabello and Carlos E. Lange are researchers from CICPBA. We thank statistician Dra. Celina Beltran, research professor of Universidad Nacional de Rosario, for performing the statistical tests of this investigation and the authors are grateful to Dr. Donald F. Haggerty, a retired career investigator and native English speaker, for editing the final version of the manuscript. We also thank two anonymous reviewers for helpful comments on the manuscript.

\section{References}

Altschul SF, Gish W, Miller W, Myers EW, Lipman DJ (1990) Basic local alignment search tool. J Mol Biol 215:403-410

Alves SB, Moino A, Almeida JEM (1998) Produtos fitossanitários e entomopatógenos. In: Alves SB (ed) Controle microbiano de insectos. FEALQ, Piracicaba, Brazil, pp 217-238

Anderson TE, Roberts DW (1983) Compatibility of Beauveria bassiana strain with formulations used in Colorado Potato Beetle (Coleoptera: Chrysomelidae) control. J Econ Entomol 76:1437-1441

Bischoff JF, Rehner SA, Humber RA (2009) A multilocus phylogeny of the Metarhizium anisopliae lineage. Mycologia 101:512-530

Bitsadze N, Jaronski S, Khasdan V, Abashidze E, Abashidze M, Latchininsky A, Samadashvili D, Sokhadze I, Rippa M, Ishaaya I, Horowitz AR (2013) Joint action of Beauveria bassiana and the insect growth regulators diflubenzuron and novaluron, on the migratory locust, Locusta migratoria. J Pest Sci 86:293-300

Boucias DG, Stokes C, Storey G, Pendland JC (1996) The effect of imidacloprid on the termite Reticulitermes flavipes and its interaction with the mycopathogen Beauveria bassiana. Pflanzenschutz-Nachr Bayer 49:103-144

CASAFE (2013) Cámara Argentina de Sanidad Agropecuaria y Fertilizantes: Guía de productos fitosanitarios. Tomo 1. CASAFE. Buenos Aires, Argentina

Delgado FX, Britton JH, Onsager JA, Swearingen W (1999) Field assessment of Beauveria bassiana (Balsamo) Vuillemin and potential synergism with diflubenzuron for control of Savanna grasshoppers complex (Orthoptera) in Mali. J Invertebr Pathol 73:34-39

Foster RN, Reuter KC, Black L, Britton J (1996) Evaluation of the fungus Beauveria bassiana with selected insecticide stressors for control of unconfined rangeland grasshoppers. Arthropod Manag Tests 21:280

Gonzalez M, Miglioranza KS, Aizpún JE, Isla FL, Peña A (2010) Assessing pesticide leaching and desorption in soils with different agricultural activities from Argentina (Pampa and Patagonia). Chemosphere 81:351-358

Hassan AEM, Charnley AK (1989) Ultrastructural study of the penetration by Metarhizium anisopliae through Dimilin affected cuticle of Manduca sexta. J Invertebr Pathol 54:117-124
Henry JE (1985) Melanoplus spp. In: Singh P, Moore RF (eds) Handbook of Insect Rearing. vol. 1'. Elsevier, Amsterdam, pp 451-464

Horowitz AR, Ishaaya I (2004) Insect pest management-field and protected crops. Springer, Berlin, Germany

Inglis GD, Johnson DL, Goettel MS (1996) Effect of bait substrate and formulation on infection of grasshopper Nymphs by Beauveria bassiana. BioControl Sci Technol 6(1):35-50

Jager T, Heugens EHW, Kooijman SALM (2006) Making sense of ecotoxicological test results: towards application of process-based models. Ecotoxicology 15(3):305-314

Jaronski ST (2010) Ecological factors in the inundative use of fungal entomopathogens. Biocontrol 55:159-185

Lacey LA, Brooks WM (1997) Initial handling and diagnosis of diseased insects. In: Lacey LA (ed) Manual of techniques in insect pathology. Academic Press, San Diego, USA, pp $1-15$

Lane BS, Humphreys BSAM, Thompson K, Trinci APJ (1988) ATP content of stored spores of Paecilomyces farinosus and the use of ATP as criterion of spore viability. Trans Br Mycol Soc 90:109-111

Lange CE (1996) Protistas patógenos de insectos terrestres. In: Lecuona R (ed) Microorganismos patógenos empleados en el control microbiano de insectos plaga. Mariano Mas, Buenos Aires, Argentina, pp 87-104

Lomer CJ, Bateman RP, Johnson DL, Langewald J, Thomas M (2001) Biological control of locust and grasshoppers. Annu Rev Entomol 44:667-702

Mariottini Y, De Wysiecki ML, Lange CE (2010) The biology and population parameters of the grasshoppers Ronderosia bergi under laboratory conditions. J Insect Sci 10:92

Mariottini Y, De Wysiecki ML, Lange CE (2011) Seasonal occurrence of life stages of grasshoppers (Orthoptera: Acridoidea) in the southern pampas, Argentina. Zool Stud 50(6):737-744

Mascarin GM, Kobori NN, Quintela ED, Arthurs SP, Júnior ID (2014) Toxicity of non-ionic surfactants and interactions with fungal entomopathogens toward Bemisia tabaci biotype B. BioControl 59:111-123

Moino AR, Alves SB (1998) Efeito de Imidacloprid e fipronil sobre Beauveria bassiana (Bals.) Vuill. e Metarhizium anisopliae (Metsch.) Sorok. e no comportamento de limpeza de Heterotermes tenuis (Hagem). An Soc Entomol Brasil 27:611-619

Moore D, Reed M, Le Patourel G, Abraham YJ, Prior C (1992) Reduction of feeding by the desert locust, Schistocerca gregaria, after infection with Metarhizium flavoviride. J Invertebr Pathol 60:304-307

Neves PMOJ, Hirose E, Tchujo PT, Moino A (2001) Compatibility of entomopathogenic fungi with neocotinoid insecticides. Neotrop Entomol 30(2):263-268

Nishimatsu T, Jackson JJ (1998) Interaction of insecticides, entomopathogenic nematodes, and larvae of the western corn rootworm (Coleoptera: Chrysomelidae). J Econ Entomol 91(2):410-418

Oliveira CN, Neves MO, Kawazoe LS (2003) Compatibility between the entomopathogenic fungus Beauveria bassiana and insecticides used in coffee plantations. Sci Agric 60(4):663-667

Paula AR, Carolino AT, Paula CO, Samuels RI (2011) The combination of the entomopathogenic fungus Metarhizium 
anisopliae with the insecticide Imidacloprid increases virulence against the dengue vector Aedes aegypti (Diptera: Culicidae). Parasit Vectors 4:1-8

Pelizza SA, Eliades LA, Scorsetti AC, Cabello MN, Lange CE (2012a) Entomopathogenic fungi from Argentina for the control of Schistocerca cancellata (Orthoptera: Acrididae) nymphs: fungal pathogenicity and enzyme activity. Biocontrol Sci Technol 22(10):1119-1129

Pelizza SA, Eliades LA, Saparrat MCN, Cabello MN, Scorsetti AC, Lange CE (2012b) Screening of Argentine native fungal strain for biocontrol of the grasshoppers Tropidacris collaris: relationship between fungal pathogenicity and chitinolytic enzyme activity. World J Microbiol Biotechnol 28:1359-1366

Pelizza SA, Mariottini Y, Russo ML, Cabello MN, Lange CE (2013) Survival and fecundity of Dichroplus maculipennis and Ronderosia bergi (Orthoptera: Acrididae: Melanoplinae) following infection by Beauveria bassiana (Ascomycota: Hypocreales) under laboratory conditions. Bicontrol Sci Technol 23(6):701-710

Péry AR, Flammarion P, Vollat B, Bedaux JJ, Kooijman SA, Garric J (2002) Using a biology-based model (DEBtox) to analyze bioassays in ecotoxicology: opportunities and recommendations. Environ Toxicol Chem 21(2):459-465

Quintela ED, Mascarin GM, Da Silva RA, Barrigossi JAF, Martins JF (2013) Enhanced susceptibility of Tibraca limbativentris (Heteroptera: Pentatomidae) to Metarhizium anisopliae with sublethal doses of chemical insecticides. Biol Control 66:56-64

Rehner SA, Buckley E (2005) A Beauveria phylogeny inferred from nuclear ITS and EF1 a sequences: evidence for cryptic diversification and links to Cordyceps teleomorphs. Mycologia 97:84-98

Reuter KC, Foster RN, Black L, Britton J (1996) Laboratory evaluation of Beauveria bassiana with an added chemical stressor. Arthropod Manag Tests 21:415-416

SAS/STAT ${ }^{\circledR}$ Version 8. The GLM Procedure (2001) SAS Institute Inc. SAS Campus drive, Cary, North Carolina, USA
Stenglein S, Balatti P (2006) Genetic diversity of Phaeoisariopsis griseola in Argentina as revealed by pathogenic and molecular markers. Physiol Mol Plant Pathol 68:158-167

van Driesche RG, Hoddle MS, Center TD (2007) Conservación de los agentes de control biológico en los cultivos. In: van Driesche RG, Hoddle MS, Center TD (eds) Control de plagas y malezas por enemigos naturales. Forest Health Technology Enterprise Team, USA, pp 391-429

Xlstat Life Software (2014) Version 2014.1.01. Addinsoft SARL Paris, France. http://www.xlstat.com

Sebastian A. Pelizza has studied the effects of entomopathogenic fungi on grasshoppers and locusts (Orthoptera: Acrididae) with the purpose of an integrated pest management.

A. C. Scorsetti has investigated the entomopathogenic fungi on horticultural pest and its interaction with natural enemies (Coleoptera: Coccinellidae).

M. N. Fogel has studied the eco-toxicology of chemical insecticides on natural enemies of insect pest.

S. G. Pacheco-Marino has studied the toxicology of pathogenic fungi on fishes.

S. A. Stenglein is expert on physiological and molecular basis of the Fusarium-Poaceae interaction.

M. N. Cabello is specialist on taxonomy of Imperfecti fungi and mycorrhizas.

C. E. Lange is specialist on biology, ecology and control of grasshoppers and locusts (Orthoptera: Acrididae). 